\title{
FERRITIN LEVEL CHANGES AND ERYTHROID IMPROVEMENT IN A GROUP OF ADULT POLYTRANSFUSED PATIENTS TREATED WITH DEFERASIROX
}

\author{
ANDRADA VIORICA PARVU' ${ }^{1}$, ANCA BOJAN ${ }^{1}$, LAURA URIAN ${ }^{1}$, \\ TUNDE TOROK ${ }^{1}$, IULIA ANDREA ZSOLDOS ${ }^{1}$, MIHAELA IANCU ${ }^{2}$
}

\author{
${ }^{1}$ Hematology Department, Iuliu Hatieganu University of Medicine and Pharmacy, \\ Cluj-Napoca, Romania \\ ${ }^{2}$ Medical Informatics and Biostatistics Department, Iuliu Hatieganu University of \\ Medicine and Pharmacy, Cluj-Napoca, Romania
}

\begin{abstract}
Background and aims. Chelating agents therapy is recommended for polytransfused patients that have evidence of iron overload (an elevated serum ferritin or received over 20 units of red blood cell transfusions). Deferasirox showed efficacy and safety in maintaining or reducing body iron. Iron chelation therapy was associated with hematopoiesis improvement in transfusion-dependent patients.

Our objectives were to analyze differences in ferritin level in adult polytransfused patients treated with Deferasirox, to estimate the erythroid improvement and variation of the number of red blood cell transfusion after introducing Deferasirox, to evaluate the side effects of the treatment.

Methods. Retrospective study including all the adult polytransfused patients treated with Deferasirox in Hematology Departments of three county hospitals in the North-West of Romania.

Results. We included 40 polytransfused patients treated with Deferasirox in standard doses. There was a significant reduction in serum ferritine from baseline for all the patients (Friedman test, $\chi 2(2)=26.82, p<0.001$ ). Safety profile of Deferasirox was good (three digestive side effects). RBCT were administered before (mean $2.43 \pm 1.09$ units/month) and after starting Deferasirox (mean $1.40 \pm 0.97$ units/month), the difference is statistically significant (Student Test, $t(39)=6.98, p<0.001$ ).

Conclusions. Deferasirox proves to be an effective iron chelator, the serum level of ferritine decreased for all the patients during the treatment and $22.5 \%$ of the patients developed an erythroid improvement. Safety and compliance were good.
\end{abstract}

Keywords: iron overload, iron chelating therapy, anemia

\section{Background and aims}

Iron overload as a consequence of chronic blood transfusions is a common clinical problem. Regular packed red blood cell (RBC) transfusions are required for many anemias produced by a decrease in red blood cell production, an increase in cell destruction, or chronic blood loss. Chronic blood transfusion therapy inevitably leads to secondary iron overload, because the human body doesn't have mechanisms to eliminate the excess of iron. This can cause significant damage to many organs, such as the liver, heart, kidneys, endocrine system. Iron overload is associated

Manuscript received: 03.11.2017

Accepted: 05.12.2017

Address for correspondence: parvuandrada@hotmail.com with the production of free radicals that can damage tissues, resulting in cardiac toxicity, endocrine dysfunction, and liver toxicity. It is very important to remove excess iron in order to avoid the serious clinical sequelae, the golden standard is iron chelating therapy $[1,2,3,4,5]$.

Patients with myelodysplastic syndromes (MDS) have deficiencies in hematopoiesis and are at increased risk for progression to acute myeloid leukemia (AML). They are a specific group of candidates for iron chelating therapy because iron overload appears because of pathogenetic mechanism of MDS and because of blood transfusions [6,7].

There are different methods for evaluating the iron overload: serum ferritin levels, liver iron concentration determined from a biopsy, superconducting quantum 
interference device (SQUID) and magnetic resonance imaging for estimating liver or heart iron. Sometimes, a combination of these tests is used to quantify and monitor iron burden. The simplest way to quantify iron overload is to test serum ferritin levels, which correlates with body iron stores or to count the number of RBC units that a patient has been transfused over time [6].

According to international guidelines, chelating therapy is recommended for transfused patients that have an elevated serum ferritin level (over 1000 microg/l), evidence of iron overload or received over 20 units of red blood cell transfusions (RBCT) [1,6].

Modern oral chelators are Deferiprone and Deferasirox, the latter available in Romania. Iron chelating with this drug may be beneficial because of its once-daily formulation, supported by its plasma half-life of 11 to 19 hours. The efficacy of Deferasirox at a dose of $20-30 \mathrm{mg} /$ $\mathrm{kg} /$ day is very good in reducing liver iron concentration and serum ferritin levels in several large randomized trial in polytransfused anemic patients. The drug is well tolerated with mild side effects like transient gastrointestinal events, including abdominal pain, nausea and vomiting, diarrhea and constipation occur in approximately $15 \%$ of patients $[1,2,6,7]$.

Iron chelating therapy was associated with hematologic (hematopoiesis) improvement in transfusiondependent patients. Definitions of hematologic improvement (according to International Working Group- IWG) after a treatment were standardized for the three hematopoietic lineages. Major erythroid response represents an increase of hemoglobin level over $2 \mathrm{~g} / \mathrm{dL}$ (for patients with pretreatment $\mathrm{Hb}<11 \mathrm{~g} / \mathrm{dL}$ ) or obtaining transfusion independence for red blood cells transfusion-dependent patients. Minor Erythroid Response represents a 1-2 g/dL increase of hemoglobin level (for patients with pretreatment $\mathrm{Hb}<11 \mathrm{~g} / \mathrm{dL}$ ) or a $50 \%$ decrease in transfusion requirements for red blood cells transfusion-dependent patients [8].

Many authors reported encouraging data about obtaining transfusion independence or hematological improvement after chelation therapy. Potential explanations are: reduction in serum ferritin levels and depletion of bone marrow iron improved hematopoiesis; immunomodulation capacity of iron chelators; repression of the mTOR pathway, which reduced myeloid leukemia tumor volume in a preclinical model; Deferasirox inhibits tumor signaling via the nuclear transcription factor NFkB; a direct effect on the neoplastic clone or the bone marrow environment $[9,10,11,12,13,14,15,16,17,18]$.

Some authors proved that interruption of Deferasirox treatment produced loss of erythroid response; in that situation, the patients regained the hematological improvement after restarting iron chelation therapy $[12,17]$.

After reviewing the literature, we conclude that further studies are needed in order to clarify the complex role of chelators in hematological improvement, imunomodulation and antitumor activity.

The main objectives of our study were: 1) to analyze differences in ferritin level in adult polytransfused patients treated with Deferasirox treatment as an iron chelator, after different periods of treatment; 2) to estimate the erythroid improvement (decreasing the number of red blood cell transfusion after introducing Deferasirox), and 3) to analyze the associations between time of treatment and number of red blood cell transfusion after introducing Deferasirox. The secondary objectives of our study were to evaluate the side effects of the treatment and to analyze the situations of treatment discontinuation.

\section{Methods}

We performed a retrospective observational study including all the adult polytransfused patients treated with Deferasirox in three counties Hematology Departments of Nord-West Romanian hospitals (Cluj, Satu-Mare, Maramures). Inclusion criteria were: adult patients; diagnosis like myelodysplastic syndrome or other anemias; polytransfused patients (over 20 red blood cell transfusion), patients treated with Deferasirox as an iron chelator.

Exclusion criteria: incomplete data files, patients that didn't accept the collection of scientific data from their files.

Criteria of Deferasirox treatment were: over 20 RBCT, serum ferritine level over 1000 microg/l.

We created a data collection sheet including: demographics, information about patients' disease and its treatment, serum ferritine level at the start and during treatment, Deferasirox dose, data about dose modification, adverse effects of Deferasirox and their management, reasons for treatment discontinuation, evaluation of comorbidities that could increase serum ferritine level, number of RBCT before and after starting the treatment.

All the patients signed the standard Informed Consent form stating that they accepted the treatment, they were informed about side effects and the consequences of a potential refusal. All the patients agreed to use their medical data for clinical research.

\section{Statistical method}

The quantitative variables with Gaussian distribution were described using mean and standard deviation as representative descriptive statistics, while quantitative variables with deviations from normal distribution were described using median and interquartile interval (lower limit = first quartile; upper limit = third quartile). Categorical variables were summarized by absolute and relatives frequencies.

The existence of significant differences regarding studied clinical characteristics was tested by Student-t test and Friedman test. The significant results of Friedman test were followed by post-hoc analyze using Nemenyi test in order to identify the source of significant differences.

All statistical tests were two-sided tests and statistical 


\section{Hematology}

significance was achieved if estimated significance level (p) was lower than 0.05 .

The statistical analysis was performed with the advanced environment for statistical computing and graphics R (v.3.4.0, Vienna, Austria) and STATISTICA version 7.0 (StatSoft Inc., Tulsa, Oklahoma, USA) software.

\section{Results}

We included 40 polytransfused patients, treated with Deferasirox, mean age $63 \pm 15.6$ years. The treatment started for some patients in 2009 and for the majority of the patients in 2011-2017, in this period the treatment was reimbursed by a national programme. The patients' diagnosis included mielodysplastic syndromes $(85 \%$ of cases), thalassemia ( $2.5 \%$ of cases), other anemias $(2.5 \%$ of cases). Myelodysplastic patients were treated with low dose chemotherapy, epigenetic treatment, red blood cell transfusions and bethatalassemic/anemic patients were transfused. All the patients fulfilled the criteria for starting Deferasirox treatment. Deferasirox dose was $20-30 \mathrm{mg} /$ $\mathrm{kg}$ and the treatment was administered for 2.5-61 months. The median time of treatment was 10 months (interquartile interval: 5.75-32.25). There were rare cases of dose modifications documented in the patients' files.

The baseline value of serum ferritine level for the whole group of patients was between 1033-11202 microg/1 with a median value of 1788 and an interquartile interval of $[1566 ; 2665]$. There was a significant reduction in serum ferritin from baseline for all the patients (Friedman test, $\quad \chi 2(2)=26.82, \quad \mathrm{p}<0.001)$. The post-hoc analysis using Nemenyi test revealed that distribution of ferritin values was significantly different between baseline and 6 months $(\mathrm{p}=0.027)$ with a decreasing level of ferritin (median[percentile25\%; percentile75\%]:1788[1566; 2665] versus $1100[740,1479])$. The similar results were found for baseline and 12 months of treatment $(p=0.014)$ with a decreasing level of ferritin (median[percentile25\%; percentile75\%]: 1788[1566; 2665] versus 980 [900; 1800]). No significant difference was found in ferritin values between 6 and 12 months of treatment $(\mathrm{p}=0.973$ ) (Figure 1).

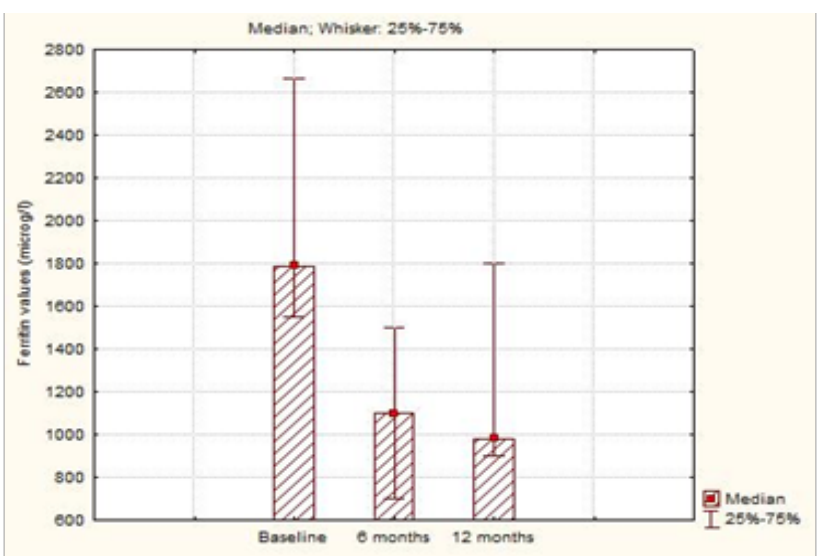

Figure 1. Decreasing of Ferritine level during Deferasirox treatment.
There were 8 patients that had descendent levels of feritin, but during infectious episodes the ferritin increased for a short period of time because ferritin represents an acute phase reactant. Three patients had very good response to the Deferasirox treatment (Ferritin level $<500 \mathrm{microg} / \mathrm{l}$ ) and the medication was discontinued, according to international protocols. For another 21 patients ferritin levels decreased during the treatment and were between 500-1000 microg/1 at the time we analyzed the group of patients.

Safety profile of Deferasirox was good. There was one temporary interruption of the treatment due to one episode of diarrhea (interpreted as a side effect, medium degree) that was treated with anti-inflammatory/antidiarrhea drugs and diet. In the entire group of patients, there were 3 definitive discontinuations of the treatment in the situation of one noncompliant patient, one patient suffering of a severe diarrhea and one patient that developed an episode of superior digestive bleeding (that could have had other causes, too).

Another research hypothesis was that the number of packed red blood cell transfusion decrease after introducing Deferasirox treatment, which means that erythropoiesis was improved after a period of Deferasirox treatment. The mean of red blood cell transfusions administered before starting the iron chelation therapy was $2.43 \pm 1.09$ units/ month for the entire lot of patients and the mean of RBCT administered after starting Deferasirox was $1.40 \pm 0.97$ units/month (see Figure 2). This difference was statistically significant (Student t-test for paired samples, $t(39)=6.98$, $\mathrm{p}<0.001$ ), after starting Deferasirox treatment mean number of RBCT decreased, mean of differences was 1.02 (95\% CI: $[0.72 ; 1.31])$.

We also analyzed the subgroup of 23 patients treated with Deferasirox for less than 12 months, and the patients treated more than 12 months, 15 patients. In both groups the difference of RBCT means before and after the start of the treatment were statistically significant (for the patients treated less than 12 months: Student t-test, $\mathrm{t}(23)=6.92$, $\mathrm{p}<0.001$ and for the patient treated more than 12 months: Student test, $\mathrm{t}(15)=3.56, \mathrm{p}=0.003)$ (Figure 2$)$.

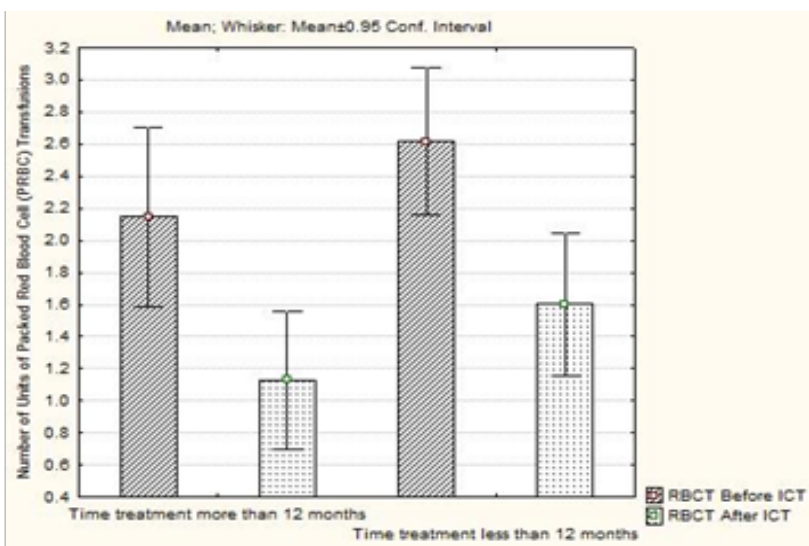

Figure 2. Decreasing the number of PRBC transfusions after starting Deferasirox treatment for whole group of patients. 
Four patients (10\%) became transfusion independent after Deferasirox treatment, this means they had a Major Erythroid Improvement according to IWG. 5 patients had more than $50 \%$ decrease in transfusion requirements, developing a Minor Erythroid Improvement. For another 4 patients the number of red blood cell transfusions decreased significantly after starting iron chelation therapy, the patients needed one transfusion of RBC every 2-3 months.

\section{Discussion}

We analyzed a group of 40 polytransfused patients treated in three counties of North-Western Romania with Deferasirox, the only modern iron chelator approved in our country. As far as we know this is the first and the only one study on a group of patients treated with Deferasirox in our country.

We studied the efficiency of this iron chelation therapy reflected in decreasing ferritin level and erythroid improvement (decreasing the number of red blood cells transfusions). According to other authors (Lyons, Poggiali), these are the simplest ways to quantify iron overload. Other methods like liver biopsy and estimating liver iron concentration, cardiac IMR and calculating T2* are used in our country only in selected cases and are not available in every medical center.

Deferasirox dose was according to international protocols $(20-30 \mathrm{mg} / \mathrm{kg})$, the treatment was administered for $2.5-61$ months and all the patients had a decreased ferritin level in the moment we picked up the data.

We compared our results to the largest trial on iron chelation therapy, EPIC, which included a large group of 1774 anemic patients, including 336 myelodysplastic syndrome patients. This trial reported a significant reduction in serum median ferritin level from baseline of $2640 \mathrm{microg} / 1$ [11]. In our small group, the reduction in serum median ferritin level from baseline at 6 months was $2094 \mathrm{microg} / \mathrm{l}$, and at 12 months was $2637 \mathrm{microg} / \mathrm{l}$. At 12 months of treatment, our the results are identical to the one reported in EPIC study. The start values of Ferritin levels in EPIC study were lower than in our small group. Baseline median serum ferritin levels in all subgroups of EPIC study were between $2500-3000 \mathrm{ng} / \mathrm{mL}$, which is a threshold known to be associated with significant negative outcomes [11]. In our group baseline median ferritin serum level was higher, 5 patients had extremely high levels, between 4220$11202 \mathrm{microg} / \mathrm{l}$. They did not have any co-morbidities that could have increased ferritin, these levels were high due to blood transfusions. Iron chelators were not available in our country when their levels of ferritine were a little over $1000 \mathrm{microg} / \mathrm{l}$. These patients had good responses to the treatment, too, but the efficacy of Deferasirox in decreasing ferritin level after one year of treatment was the same.

Another method of measuring the efficacy of chelator treatment is to study the hematopoietic improvement, materialized in decreasing of the number of red blood cell transfusions. In our group, in case of $32 \%$ of the patients, the number of red blood cell transfusion decreased. According to IWG, $10 \%$ of our patients developed a Major Erythroid Improvement and $12.5 \%$ developed a Minor Erythroid Improvement. In EPIC trial, $11.3 \%$ of the patients had a transfusion-only erythroid response, the authors did not specify if this percent represents a Major Erithroid response or Major and Minor Erithroid Response [9,11].

In the EPIC trial, the most common adverse events were gastrointestinal disturbances (28\%) and skin rash $(10 \%)$. In our group, three patients had gastrointestinal side effects (one episode of mild diarrhea, one episode of severe diarrhea and one superior digestive bleeding) [11].

We interpreted the data considering the limits of our study: it is a retrospective one, the data were collected from paper files of the patients and maybe some side effects were not noticed.

\section{Conclusion}

Analyzing our group of 40 patients, Deferasirox proves to be an effective iron chelator, the serum level of Ferritin decreased for all the patients during the treatment. Three patients stopped the treatment because ferritin levels decreased under 500 microg/l.

Safety and compliance were good. Adverse effects determined a temporary stop of the treatment for a medium degree diarrhea and definitive stop of the treatment in two cases (severe diarrhea and an episode of superior digestive bleeding).

$22.5 \%$ of the patients developed an erythroid improvement (10\% Major Improvement and $12.5 \%$ Minor Improvement), materialized by decrease of the number of red blood cell transfusion.

\section{References}

1. Poggiali E, Cassinerio E, Zanaboni L, Cappellini MD. An update on iron chelation therapy. Blood Transfus. 2012;10(4):411-422.

2. Shander A, Cappellini MD, Goodnough LT. Iron overload and toxicity: the hidden risk of multiple blood transfusions. Vox Sang. 2009;97:185-197.

3. Shenoy N, Vallumsetla N, Rachmilewitz E, Verma A, Ginzburg Y. Impact of iron overload and potential benefit from iron chelation in low-risk myelodysplastic syndrome. Blood. 2014;124:873-881.

4. Temraz S, Santini V, Musallam K, Taher A. Iron overload and chelation therapy in myelodysplastic syndromes. Crit Rev Oncol Hematol. 2014;91:64-73.

5. Neukirchen J. Iron chelation in MDS: still a controversial issue. Leuk Res. 2014;38:145-146.

6. Lyons MR, Marek BJ, Paley C, Esposito J, McNamara K, Richards PD, et al. Relation between chelation and clinical outcomes in lower-risk patients with myelodysplastic syndromes: Registry analysis at 5 years. Leuk Res. 2017;56:88-95.

7. Mainous AG 3rd, Tanner RJ, Hulihan MM, Amaya M, Coates TD. The impact of chelation therapy on survival in transfusional iron overload: a meta-analysis of myelodysplastic syndrome. Br J Haematol. 2014;167:720-723. 
8. Cheson BD, Bennett JM, Kantarjian H, Pinto A, Schiffer CA, Nimer SD, et al. Report of an international working group to standardize response criteria for myelodysplastic syndromes. Blood. 2000;96:3671-3674.

9. Gattermann N, Finelli C, Della Porta M, Fenaux P, Stadler M, Guerci-Bresler A, et al. Hematologic responses to deferasirox therapy in transfusion-dependent patients with myelodysplastic syndromes. Haematologica. 2012;97(9):1364-1371.

10. Nolte F, Höchsmann B, Giagounidis A, Lübbert $M$, Platzbecker U, Haase D, et al. Results from a 1-year, open-label, single arm, multi-center trial evaluating the efficacy and safety of oral Deferasirox in patients diagnosed with low and int-1 risk myelodysplastic syndrome (MDS) and transfusion-dependent iron overload. Ann Hematol. 2013;92(2):191-198.

11. Cappellini MD, Porter J, El-Beshlawy A, Li CK, Seymour JF, Elalfy M, et al. Tailoring iron chelation by iron intake and serum ferritin: the prospective EPIC study of deferasirox in 1744 patients with transfusion-dependent anemias. Haematologica. 2010;95(4):557-566.

12. Kochhar H, Leger CS, Leitch HA. Durable Red Blood Cell Transfusion Independence in a Patient with an MDS/ MPN Overlap Syndrome Following Discontinuation of Iron Chelation Therapy. Case Rep Hematol. 2015;2015:253294. doi: $10.1155 / 2015 / 253294$.

13. List AF, Baer MR, Steensma DP, Raza A, Esposito J, Martinez-
Lopez N, et al. Deferasirox reduces serum ferritin and labile plasma iron in RBC transfusion-dependent patients with myelodysplastic syndrome. J Clin Oncol. 2012;30(17):2134-2139.

14. Molteni A, Riva M, Pellizzari A, Borin L, Freyrie A, Greco R, et al. Hematological improvement during iron-chelation therapy in myelodysplastic syndromes: the experience of the "Rete Ematologica Lombarda”. Leuk Res. 2013,37(10):1233-1240.

15. Angelucci E, Santini V, Di Tucci AA, Quaresmini G, Finelli C, Volpe A, et al. Deferasirox for transfusion-dependent patients with myelodysplastic syndromes: safety, efficacy, and beyond (GIMEMA MDS0306 Trial). Eur J Haematol. 2014;92(6):527-536. 16. Ohyashiki JH, Kobayashi C, Hamamura R, Okabe S, Tauchi T, Ohyashiki K. The oral iron chelator deferasirox represses signaling through the mTOR in myeloid leukemia cells by enhancing expression of REDD1. Cancer Sci. 2009;100(5):970-977.

17. Messa E, Carturan S, Maffè C, Pautasso M, Bracco E, Roetto A, et al. Deferasirox is a powerful NF-kappaB inhibitor in myelodysplastic cells and in leukemia cell lines acting independently from cell iron deprivation by chelation and reactive oxygen species scavenging. Haematologica. 2010;95(8):1308-1316.

18. Ren X, Dorrington KL, Maxwell PH, Robbins PA. Effects of desferrioxamine on serum erythropoietin and ventilatory sensitivity to hypoxia in humans. J Appl Physiol (1985). 2000;89(2):680-686. 